\title{
IMPLEMENTASI REMOTE METHOD INVOCATION (RMI) UNTUK TES ONLINE INTERAKTIF MULTIUSER PADA LOCAL AREA NETWORK (LAN)
}

\author{
Adrian Nathaniel Wikana ${ }^{(1)}$, Joko Purwadi ${ }^{(2)}$, Restyandito ${ }^{(3)}$
}

\begin{abstract}
Abstrak: Teknologi informasi telah berkembang dengan pesat dan membawa banyak paradigma perubahan dalam aktivitas manusia dalam betajar dan bekerja. Perkembangan teknologi informasi saat ini cenderung mengarah pada sistem terdistribusi (client/server) dimana fungsi sebuah komputer dapat digunakan secara terkoordinasi dengan beberapa komputer lainnya. Perkembangan tersebut dituntut untuk agar dapat dioperasionalkan dan dimanfaatkan secara optimal di berbagai bidang. Dalam bidang pendidikan perkembangan teknologi client/server dapat dimanfaatkan untuk membuat sistem ujian terkomputerisasi. Salah satu metode teknologi client/server adalah RMI. Artikel ini membahas bagaimana implementasi RMI pada tes online termasuk didalamnya teknologi tambahan yang dibutuhkan untuk mendukung pengimplementasian, dan keunggulan teknologi ini.
\end{abstract}

Kata Kunci: Remote Method Invocation (RMI), Server, Client, Database Server, Java Database Connectivity (JDBC)

\section{Pendahuluan}

Teknologi informasi telah berkembang dengan pesat dan membawa banyak paradigma perubahan dalam aktivitas manusia dalam belajar dan bekerja. Perkembangan teknologi informasi saat ini cenderung mengarah pada sistem terdistribusi (client/server) dimana fungsi sebuah komputer tidak hanya terbatas pada mesin mandiri, tetapi dapat juga digunakan secara terkoordinasi dengan beberapa komputer lainnya. Perkembangan tersebut dituntut untuk dapat dioperasionalkan dan dimanfaatkan secara optimal di berbagai bidang.

Bidang pendidikan adalah salah satu bidang yang dapat memanfaatkan perkembangan teknologi client/server. Salah satu bentuk pemanfaatan teknologi client/server di bidang pendidikan yang menunjang perkuliahan adalah tes online. Remote
Method Invocation (RMI) adalah salah satu metode dalam sistem terdistribusi yang dapat diimplementasikan untuk tes online. Penulisan artikel ini membahas implementasi RMI untuk Tes Online pada Local Area Network (LAN).

\section{Landasan Teori}

Program aplikasi modem yang ada dan berkembang saat ini cenderung mengarah pada model client/server. Client/server ditandai dengan adanya request atau permintaan suatu informasi ke server dan respon atau hasil pemrosesan yang dikembalikan ke client dari server. Perkembangan program client/server yang cukup pesat saat ini mempengaruhi model pemrograman yang ada menjadi berbasis client/server pula. Java dengan Remote Method Invocation (RMI) merupakan salah

") Adrian Nathaniel Wikana, Mahasiswa Teknik Informatika, Fakulias Teknik, Universitas Kristen Duta Wacana

(2) Joko Purwadi, S.Kom, M.Kom, Dosen Teknik Inforrnatika, Fakultas Teknik, Universitas Kristen Duta Wacana

(3) Restyandito, S. Kom, MSIS, Dosen Teknik Inforrnatika, Fakultas Teknik, Universitas Kristen Duta Wacana 
satu teknik pemrograman client/server tersebut. Untuk sebuah aplikasi yang membutuhkan koneksi dengan database server maka dibutuhkan metode yaitu Java Database Connectivity (JDBC) yang dapat mengbungkan aplikasi Java dengan database server.

Pada bagian ini akan dijelaskan secara teoritis tentang konsep client/server, Java Remote Method Invocation (RMI) danJava Database Connectivity (JDBC).

\subsection{Client/Server}

Client/Server mempakan item proses atau logika terpisah yang bekerja sarna pada suatu jaringan komputer untuk mengerjakan suatu tugas tertentu. Dalarn sebuah arsitektur client/server, client berperan dalarn mengambil data dari user dan melakukan pengiriman ke server. Server berperan dalarn proses penerimaan data dari client, melakukan pemrosesan berdasarkan permintaan tersebut, dan mengembalikan ke client sebagai hasil pemrosesan yang sudah dilakukan. Sebuah server dapat melayani beberapa client.

Komputer yang meminta layanan (request) disebut sebagai client, sedangkan yang menyediakan layanan (respon) disebut sebagai server.

Client-Server memiliki beberapa karakteristik sebagai berikut:

1. Multitasking: Server dapat melayani beberapa client pada saat yang sama dan mengatur pengaksesan sumberdaya.

2. Adanya pemisahan tier dan fungsi sistem: Client/Server memisahkan tier dan layanan menjadi presentation, business logic dan data tier. Dengan pemisahan ini beban komputasi antara server dan client menjadi seimbang, dan server dapat diakses oleh beberapa client (multiuser).

\subsection{Java Remote Method Invocation (RMI)}

RMI dapat didefinisikan sebagai sebuah fasilitas standar Java yang menangani pemanggilan (invocation) suatu method secara jarak jauh (remote) dalarn suatu jaringan ${ }^{(4)}$. Method yang dipanggil tersebut ada pada komputer server dan dipanggil secara remote oleh komputer client pada suatu jaringan.

Distribusi aplikasi RMI terdiri dari dua buah program yang terpisah yaitu program server dan program client. Program server bertugas membuat beberapa remote objek dan mendaftarkan (bind) remote objek tersebut ke RMI Registry dengan nama yang unik. Program client bertugas membuat koneksi ke server dan meminta pemanggilan ke remote objek berdasar referensi yang diterimanya dari $R M I$ Registry. RMI Registry berfungsi mengkonversi nama objek yang didaftarkan (bind) oleh server menjadi remote objek reference. Remote Objek Reference adalah referensi yang berisi methodmethod yang dapat dipanggil secara remote oleh client. Referensi tersebut dibutuhkan oleh client agar dapat mengetahui dan memanggil remote method pada server. Method yang bisa dipanggil secála remote (remote method) punya remote inteiface ${ }^{(5)}$. Remote inteiface mendefinisikan metode-metode yang bisa diakses secara remote. Remote inteiface dapat berupa prosedur atau fungsi.

Mekanisme kerja yang ada pada sebuah aplikasi RMI dimulai saat RMI server akan mendaftarkan remote objeknya ke RMI Registry. Proses ini disebut dengan bind, yaitu mendaftarkan sebuah objek dengan suatu nama yang unik. Dengan terdaftarnya remote objek di RMI Registry maka RMI Registry dapat memberikan referensi ke $R M I$

\footnotetext{
(4) Budi Susanto, 2003, Pemrograman Client/Server Dengan Java2, Jakarta, Elex Media Komputindo, hlm. 137.

(s) Ibid., hlm.173.
} 
Client, tentang remote objek mana yang bisa diakses saat RMI Client melakukan pemanggilan method (request). Setelah referensi diperoleh, RMI Client dapat memanggil method yang ada di server, secara remote. RMI Server mengirimkan respon setelah dilakukan pemrosesan ke RMI Client.

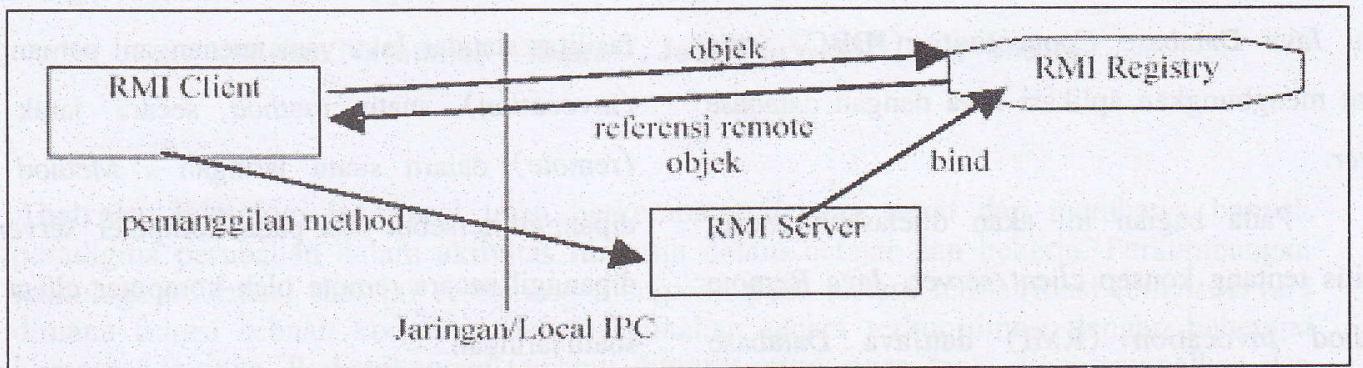

Gambar 1. Mekanisme Kerja Remote Method Invocation (RMI)

Untuk membuat aplikasi client/server berbasis RMI ada empat class yang harus didefinisikan:

\section{a. Class remote interface}

public interface tes extends java.rmi.Remote \{

public void setlawaban(String text)

Throws java.rmi.RemoteException;

public String getStatus()

throws java. rmi. RemoteException;

\}

\section{b. Class implementasi dari interface}

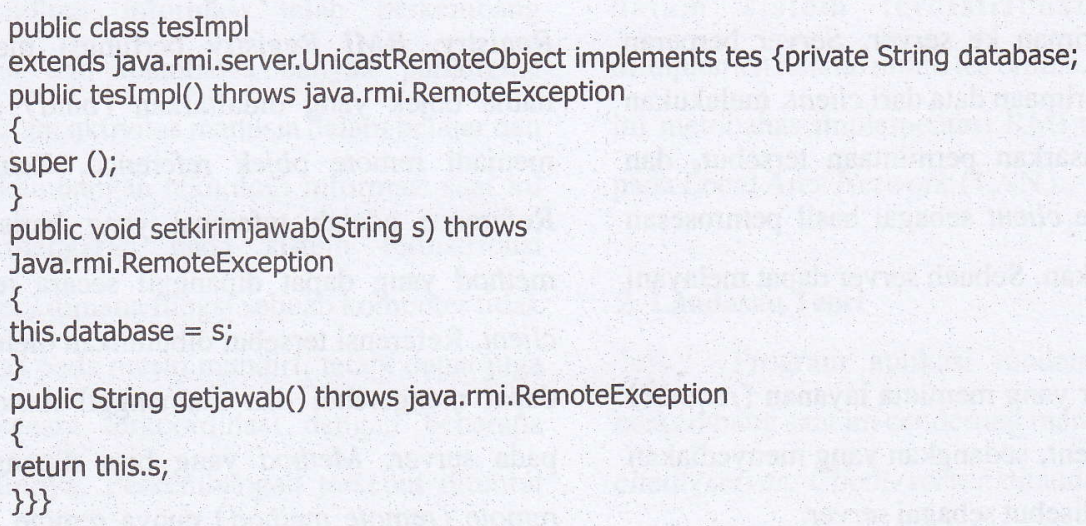

\section{c. Class Remote Server (Server)}

import java.rmi.Naming;

public class SoalServer \{ public SoalServer() \{

try \{

tes server $=$ new tesImpl();

Naming.rebind("rmi://localhost:1099/tes",server) ;

\}

catch (Exception e) \{\}$\}$

public static void main (String args[]) \{ new Server(); \}\}

\section{Class Remote Client (Client)}

import java.rmi.Naming; import java.rmi.RemoteException; 
Wikana, Implementasi RMI Untuk Tes Online Interaktif Multiuser pada LAN 9 import java.net.MalformedURLException;

import java.rmi.NotBoundException;

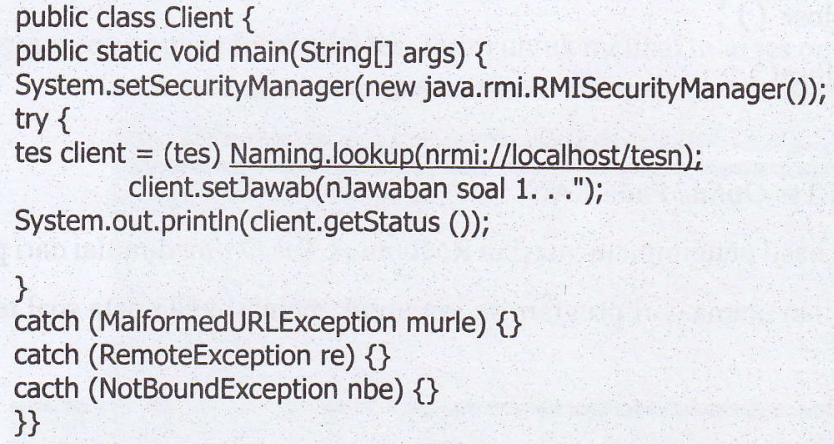

\subsection{Java Database Connectivity (JDBC)}

JDBC merupakan middleware database yang dapat menghubungkan aplikasi Java dengan database server. Untuk dapat menghubungkan aplikasi Java dengan database melalui JDBC ada beberapa langkah yang perlu dilakukan yaitu $^{(6)}$ :

\section{a. Mengakses JDBC driver}

Contoh: Class. forName, (' com.postgresql. Driver' ');

b. Mempersiapkan koneksi ke database yang dibuat lewat class Connection, dan class DriverManager. DriverManager adalah class yang digunakan untuk memilih database driver dan membuat koneksi ke database tersebut

Contoh: Connection con $=$

DriverManager.getConnection(" jdbc:postgresql", usrnm,pswd);

c. Mempersiapkan objek untuk menerima perintah SQL lewat class Statement. Class Statement digunakan untuk mendefinisikan metode yang berhubungan dengan pemyataan Structured Query Language (SQL). Contoh: Statement stat $=$ con.createStatement();

d. Mengeksekusi perintah SQL. Untuk pengaksesan hasil pemyataan SQL digunakan inteiface ResultSet. Untuk mengeksekusi perintah yang dapat mengambil data digunakan perintah executeQueryf' '). Untuk mengeksekusi perintah yang dapat memasukkan data, atau mengubah data digunakan perintah executeUpdate( (").

Contoh: ResultSet hasilQuery = null;

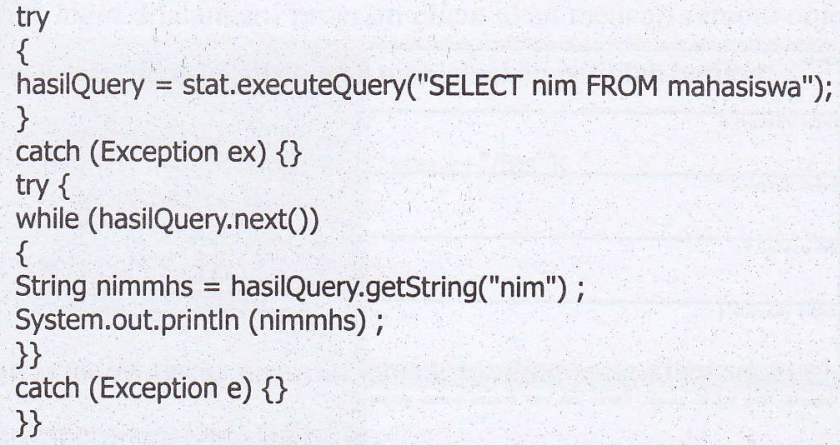

${ }^{(6)}$ Rangsang Pumama, 2005, Tuntunan Penrograman Java Jilid 3, Prestasi Pustaka, Jakarta, hlm.123. 
e. Menutup perintah dan koneksi yan gtelah dibuka

Contoh: $\quad$ stat. close ();

Con.close();

\section{Basil Implementasi RMI Untuk Tes Online Pada LAN}

Pada bagian ini disajikan hasil pengimplementasian RMI untuk Tes Onlinedimulai dari program server sampai program client. Tampilan utama dari program server untuk memasukkan data soal tes dapat dilihat pada Gambar 2.

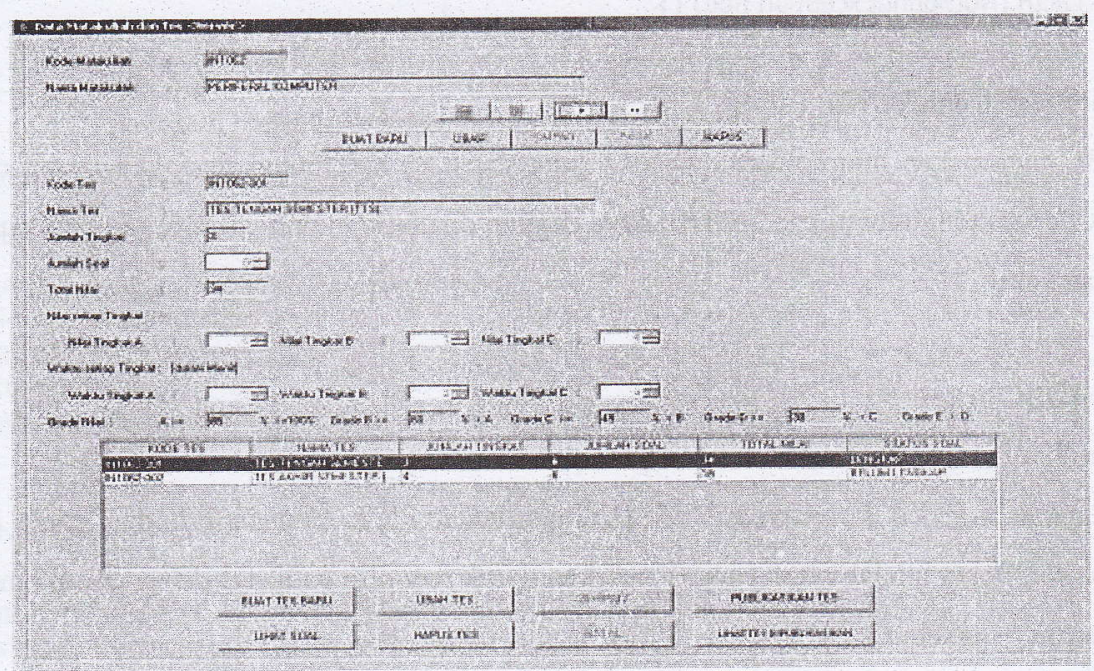

Gambar 2. Program Server- Form Data Tes Online

Pada form diatas program RMI Server akan di bind ke RMI Registry. Proses bind dijalankan dengan mengeksekusi perintah berikut:

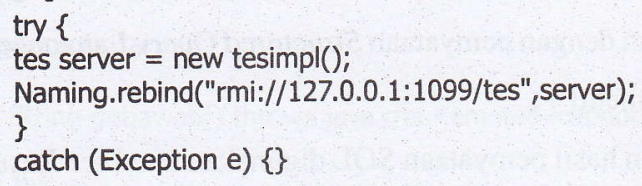

Berikutnya administrator dapat memasukkan soal tes pada form yang ditunjukkan pada gambar 3.

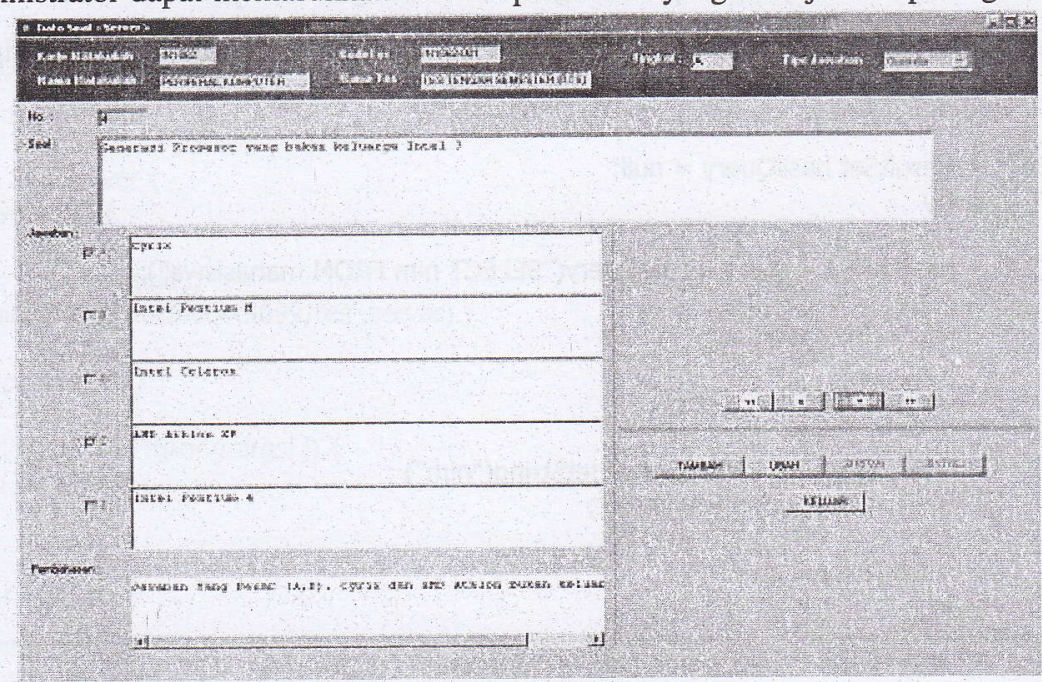

Gambar 3. Program Server - Form Soal 
Wikana, Implementasi RMI Untuk Tes Online Interaktif Multiuser pada LAN 11

Berikutnya jika tes online sudah selesai, administrator dapat melihat hasil nilai tes online yang sudah masuk ke program server pada form nilai tes. Form untuk melihat nilai tes online ditunjukkan pada gambar 4 .

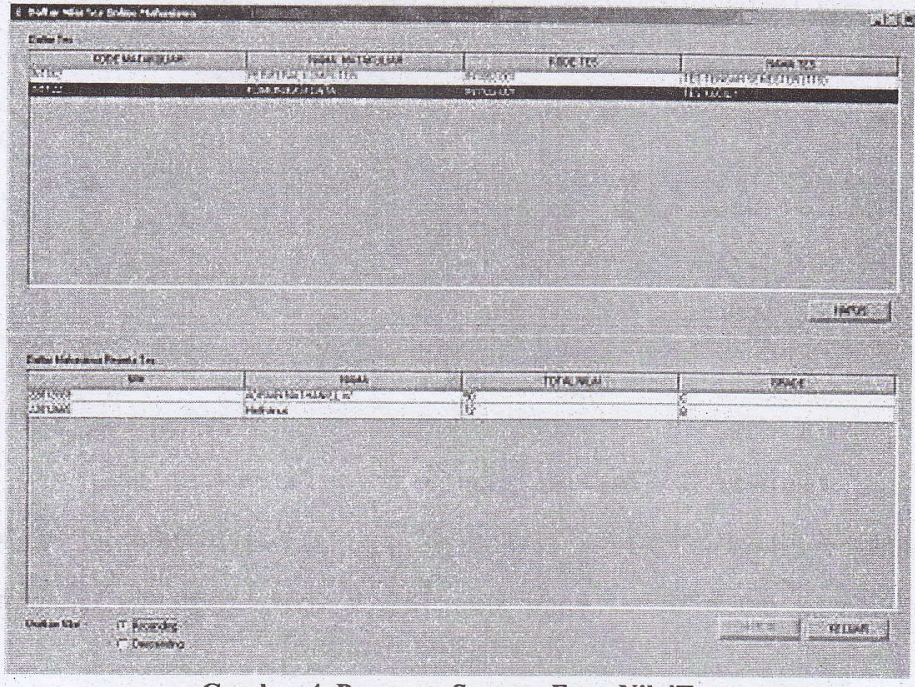

Gambar 4. Program Server - Form NilaiTes

Pada form server gambar 3 dan 4 method yang dieksekusi adalah Java Database Connectivity (JDBC) untuk menyimpan atau membaca data dari database.

Berikutnya adalah hasil pengimplementasian program RMI Client untuk Tes Online. Tampilan utama dari program client untuk login ke system server ditunjukkan pada gambar 5.

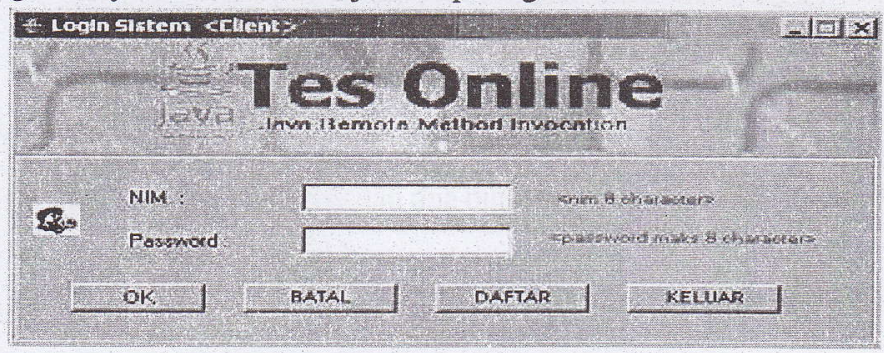

Gambar 5. Program Client - Form Login

Dengan dijalankannya program client maIm pemanggilan method pada program Server mulai dikerjakan. Method pada RMI Server yang dipanggil oleh RMI Client pada form login adalah method login, method daftar. Program server yang diimplementasikan pada class implementasi interface (teslmpI) mengeksekusi method Java Database Connectivity (JDBC) Ulltuk melakukan operasi dengan database.

Pada saat form login dijalankan, program client akan mencari remote objek reference (lookup) pada RMI Registry di server. Proses dikerjakan dengan menjalankan perintah berikut:

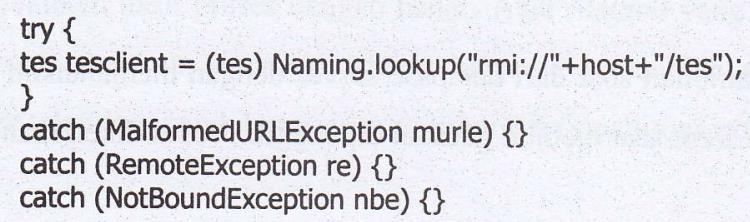

Berikutnya peserta tes dapat memilih jenis tes online yang ditawarkan oleh server yang ditunjukkan pada gambar 6. 


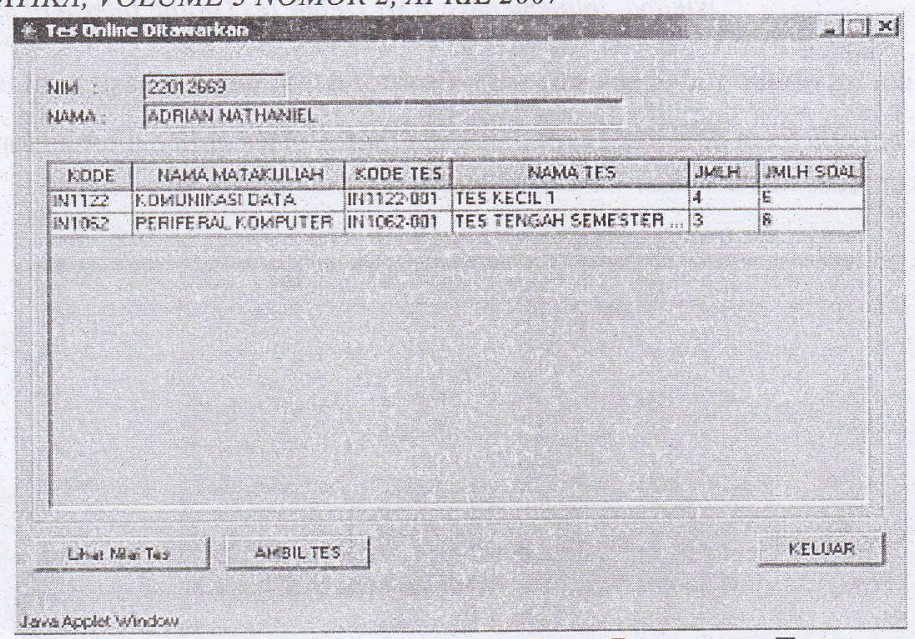

Gambar 6. Program Client - Form Penawaran Tes

Method yang dipanggil pada RMI Server pada form penawaran adalah method setTes, method mulai. Berikutnya setelah peserta tes memilih tes yang akan diikuti maka form tes untuk menjawab soal akan dijalankan, seperti tampak pada gambar 7 .

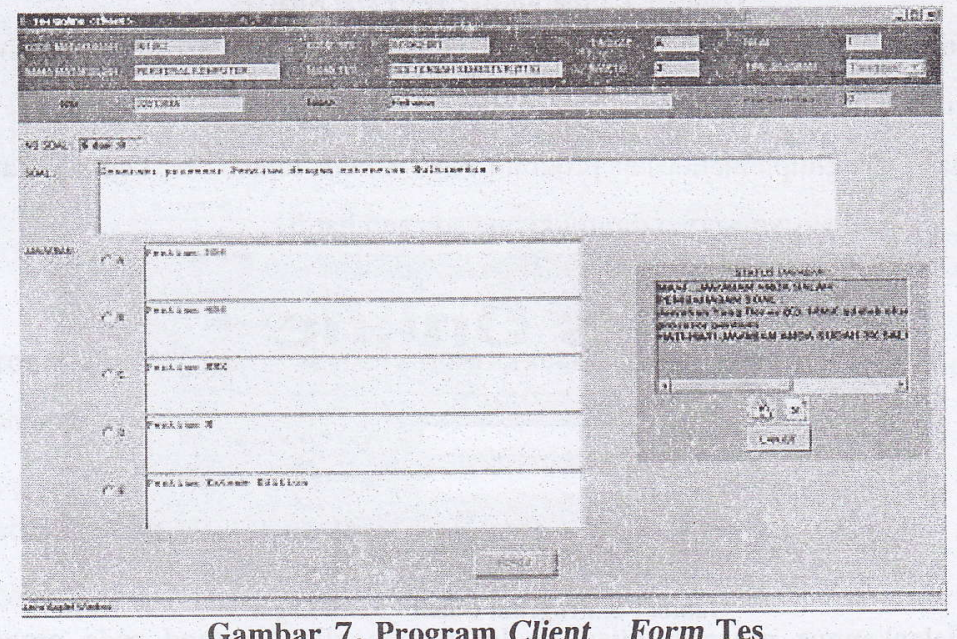

Gambar 7. Program Client _ Form Tes

Pada Form Tes gambar 7, RMI Client akan memanggil method pada RMI Server secara remote. Method yang dipanggil adalah method setSoal, getSoal, setJawaban, getPembahasan.

Proses RMI Client memanggil method setSoal untuk mengambil soal dari server dikerjakan dengan perintah berikut:

tesclient.setSoal(this.kodetes,no);

String soal $=$ tesclient.getSoal() ;

Proses pada RMI Server yaitu dilakukan pengambilan soal dari database server dengan menjalankan method setSoal dan mengembalikan data soal ke RMI Client saat method getSoal dipanggil. Proses dikerjakan dengan perintah berikut:

public synchronized void setSoal(String kode,int no) \{

this.kodetes=kode. $\operatorname{trim}()$;

this.tingkat=tgkt.trim();

this. nosoal=no;

try \{

Class.forName("org.postgresql.Driver"); 
con

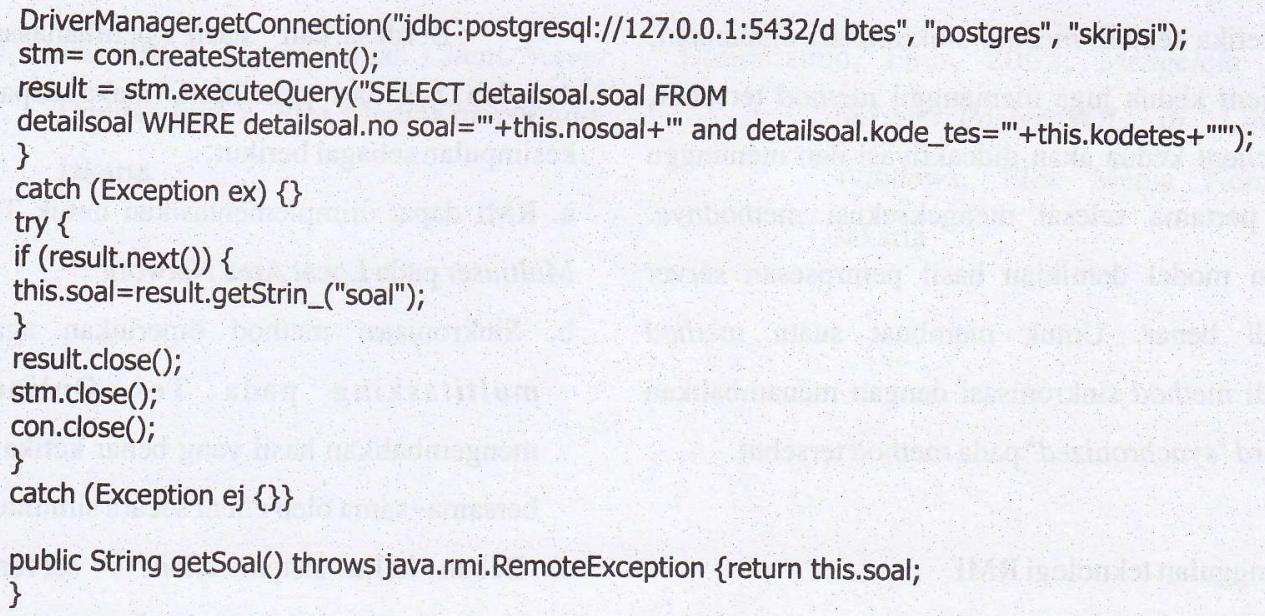

Berikutnya setelah tesonline berakhir maka akan ditampilkan hasil nilai tes pada program RMI Client yang ditunjukkan pada gambar 8.

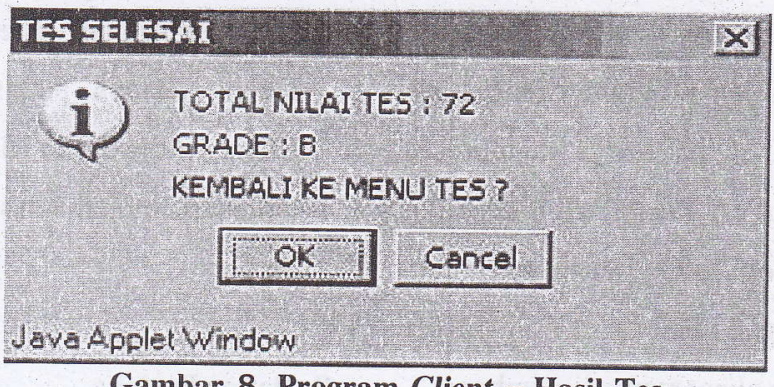

Gambar 8. Program Client - Hasil Tes

Program client/server Implementasi RMI Untuk Tes Online tersebut diujikan dengan sampling tiga buah komputer yaitu sebuah komputer sebagai server, dan dua buah komputer sebagai client.

\section{Analisis Hasil Penelitian}

Pada sub bab ini akan diuraikan analisis'dari implementasi Remote Method Invocation (RMI) pada kasus Tes Online. AnaIisis diuraikan dengan konsep dan teori Client/Server sebagai berikut:

\section{a. RMI kaitannya dengan karakteristik Client/Server Multitasking}

Proses pada RMI Server memungkinkan untuk diakses oleh sejumlah client secara bersama-sama atau dikenal dengan istilah Multitasking. ] (MI Server hams mampu melayani pennintaan simultan ini dan mengembalikan hasil proses dengan benar. Agar method yang dipanggil tersebut dapat mengembalikan hasil yang benar meskipun dipanggil secara bersama-sama oleh sejumlah client, maim method tersebut hams mendapat teknologi pendukung yaitu sinkronisasi (synchronized).

\section{b. Sinkronisasi Method}

Proses yang dikerjakan dengan sinkronisasi yaitu pemanggilan method oleh suatu client pada suatu objek server akan diproses dan diselesaikan dahulu sebelum method tersebut memproses pemanggilan dari client 
lain. Ketika sebuah method sinkronisasi dijalankan, dan client kedua juga memanggil method tersebut, maka client kedua akan dideaktivasi dan menunggu client pertama selesai mengeksekusi methodnya. Dengan model demikian hasil pemrosesan server menjadi benar. Untuk membuat suatu method menjadi method sinkronisasi dengan menambahkan keyword "synchronized" pada method tersebut.

\section{c. Keunggulan teknologi RMI}

Beban komputasi server dan client seimbang. Program RMI adalah hasil kolaborasi RMI Server dan RMI Client. Pada RMI tidak semuanya harus dikerjakan oleh program server, sebagian proses dapat dikeljakan oleh program client. Pada kasus Tes Online, RMI Server hanya memproses pengaksesan database server. Proses tes dikerjakan RMI Client, seperti random, menyimpan array data tes beserta nilainya. Dengan pembagian fungsi RMI ini maka beban server dan client menjadi seimbang.

\section{d. Perbandingan RM1 dengan Metode Client/Server lainnya \\ RM1 mempunyai perbedaan dengan} metode client/server lainnya seperti PHP. Perbedaan tersebut dapat ditinjau dari pemrosesan yang dilakukan. Pemrosesan business logic RMI dapat dikerjakan pada server maupun client. Pemrosesan business logic pada PHP hanya dapat dikerjakan pada server (server side scripting). Untuk pengembangan aplikasi skala Enterprise RMI mempunyai unjuk kerja yang lebih baik. Namun sistem yang dibutuhkan untuk pengembangan aplikasi dengan RMI juga. jauh lebih kompleks dan rumit dibanding teknologi PHP yang sudah banyak digunakan.
Berdasarkan hasil pembahasan kajian dan_analisis dari penelitian, maka dapat diambil kesimpulan sebagai berikut:

a. RMI dapat diimplementasikan untuk Tes Online Multiuser pada Local Area Network

b. Sinkronisasi method diperlukan agar proses multitasking pada Tes Online dapat mengembalikan hasil yang benar ketika dipanggil bersama-sama oleh client secara simultan

c. Beban keIja sistem client / server menjadi seimbang dan unjuk kerja sistem menjadi lebih handal karena adanya pembagian fungsi antara RMI Server dan RMI Client.

d. Pengembangan sistem menjadi lebih mudah, karena adanya pemisahan tier. Program RMI Client tidak perlu diubah jika ada perubahan terhadap implementasi business logic pada RMI Server.

\section{Daftar Pustaka}

Coulouris, George., Jean Dollimore, Tim Kindberg, 2001, Distributed Systems Concepts and Design Third Edition, Addison Wesley, Amerika

Deitel, H.M. , Deitell, P.I., 1997, Java How To Program, Prentice Hall, New Jersey

Horstmann, Cay S., Gary Cornell, 2000, Core Java 2 Volume II-Advanced Features, Sun Microsystems Press, California, USA

Indrajani, Martin, 2004, Pemrograman Berorientasi Objek dengan JA VA, Elex Media Komputindo, Jakarta

Kadir, Abdul., 2004, Dasar Pemrograman Java 2, Penerbit ANDI, Y ogyakarta

Purnama, Rangsang. , 2005, Tuntunan Pemrograman Java Jilid 3, Prestasi

\section{Kesimpulan}

Pustaka, Jakarta 
Wikana, Implementasi RMI Untuk Tes Online Interaktif Multiuser pada LAN 15 Susanto, Budi, 2003, Pemrograman Client/Server Utdirartatmo, Firar, 2002, Mengelola Database Dengan Java 2, Elex MediaKomputindo, Server PostgreSQL di Linux dan Jakarta

Windows, Elex Media Komputindo, Jakarta 